Gynäk. Rdsch. 1983;23(suppl. 1):I-IV

\title{
Contents, Vol. 23, Supplement 1, 1983
}

Tioconazole, a New Broad-Spectrum Antifungal Agent:

Preclinical Studies Related to Vaginal Candidiasis

Marriott, M.S.; Brammer, K.W.; Faccini, J.; Faulkner, J.K.; Jevons, S.;

Monro, A.M.; Nachbaur, J.; Perraud, J.; Tarbit, M.H 1

Open Studies of the Efficacy, Tolerance, Systemic Absorption and

Vaginal Persistence following a Single Application of Tioconazole

Ointment in the Treatment of Patients with Vaginal Candidiasis

Artner, J.; Fuchs, G 12

Double-Blind Comparison of the Efficacy, Tolerance and Safety of

Tioconazole and Placebo in Patients with Vaginal Candidiasis

and the Assessment of Systemic Absorption

Artner, J.; Fuchs, G 20

Open Comparison of the Efficacy, Toleration and Safety of

Tioconazole Cream and Econazole Ovules Used in the 3-Day

Treatment of Patients with Vaginal Candidiasis

Cohen, J 25

Open Comparison of the Efficacy, Toleration and Safety of

Tioconazole and Econazole in the 3-Day Treatment of Vaginal

Candidiasis

Krohn, K.; Vinnerberg, A 29

Open Comparison of the Efficacy, Toleration and Safety of

Tioconazole Cream Used for either 3- or 6-Day Treatment of

patients with Vaginal Candidiasis

Oittner, R 33

Short-Term Treatment of Trichomonas vaginalis with Tioconazole

Cream, a New Antifungal Agent

Yoffe, C.A.; Katz, E.A 37

Tioconazole in the Treatment of Vaginal Candidiasis. An International Clinical Research Program Report prepared by Henderson, J.T.; Neilson, W.; Wilson, A.B.; Jevons, S. . 42 Author Index Subject Index

6161 